Article

\title{
Quick, Easy, and Economic Mineralogical Studies of Flooded Chalk for EOR Experiments Using Raman Spectroscopy
}

\author{
Laura Borromeo $^{1,2, *} \mathbb{1}$, Nina Egeland ${ }^{1,2}$, Mona Wetrhus Minde ${ }^{1,2}$, Udo Zimmermann ${ }^{1,2}$, \\ Sergio Andò ${ }^{3}$ (D), Merete Vadla Madland ${ }^{1,2}$ and Reidar Inge Korsnes ${ }^{1,2}$ \\ 1 Department of Energy Resources, University of Stavanger, 4036 Stavanger, Norway; \\ nina.sivertsen@gmail.com (N.E.); mona.w.minde@uis.no (M.W.M.); udo.zimmermann@uis.no (U.Z.); \\ merete.v.madland@uis.no (M.V.M.); reidar.i.korsnes@uis.no (R.I.K.) \\ 2 The National IOR Centre of Norway, 4036 Stavanger, Norway \\ 3 Department of Earth and Environmental Sciences, University of Milano-Bicocca, 20126 Milano, Italy; \\ sergio.ando@unimib.it \\ * Correspondence: laura.borromeo@uis.no; Tel.: +39-338-600-8504
}

Received: 16 February 2018; Accepted: 17 May 2018; Published: 23 May 2018

\begin{abstract}
Understanding the chalk-fluid interactions and the associated mineralogical and mechanical alterations on a sub-micron scale are major goals in Enhanced Oil Recovery. Mechanical strength, porosity, and permeability of chalk are linked to mineral dissolution that occurs during brine injections, and affect the reservoir potential. This paper presents a novel "single grain" methodology to recognize the varieties of carbonates in rocks and loose sediments: Raman spectroscopy is a non-destructive, quick, and user-friendly technique representing a powerful tool to identify minerals down to $1 \mu \mathrm{m}$. An innovative working technique for oil exploration is proposed, as the mineralogy of micron-sized crystals grown in two flooded chalk samples (Liége, Belgium) was successfully investigated by Raman spectroscopy. The drilled chalk cores were flooded with $\mathrm{MgCl}_{2}$ for ca. 1.5 (Long Term Test) and 3 years (Ultra Long Term Test) under North Sea reservoir conditions (Long Term Test: $130{ }^{\circ} \mathrm{C}, 1 \mathrm{PV} /$ day, $9.3 \mathrm{MPa}$ effective stress; Ultra Long Term Test: $130{ }^{\circ} \mathrm{C}$, varying between 1-3 PV/day, 10.4 MPa effective stress). Raman spectroscopy was able to identify the presence of recrystallized magnesite along the core of the Long Term Test up to $4 \mathrm{~cm}$ from the injection surface, down to the crystal size of 1-2 $\mu \mathrm{m}$. In the Ultra Long Term Test core, the growth of $\mathrm{MgCO}_{3}$ affected nearly the entire core $(7 \mathrm{~cm})$. In both samples, no dolomite or high-magnesium calcite secondary growth could be detected when analysing 557 and 90 Raman spectra on the Long and Ultra Long Term Test, respectively. This study can offer Raman spectroscopy as a breakthrough tool in petroleum exploration of unconventional reservoirs, due to its quickness, spatial resolution, and non-destructive acquisition of data. These characteristics would encourage its use coupled with electron microscopes and energy dispersive systems or even electron microprobe studies.
\end{abstract}

Keywords: flooded chalk; Raman spectroscopy; Enhanced Oil Recovery; carbonates; calcite; magnesite

\section{Introduction}

Injection of seawater-like brines is one of the most successful Improved Oil Recovery (IOR) methods on the Norwegian Continental Shelf (amongst many others: [1,2]). The mechanical strength of chalk is weakened by seawater at reservoir temperatures, and as a consequence, compaction and loss in porosity occur, affecting the oil recovery factor of carbonate fields [3-10]. It is important to understand how fluids interact with rocks, because textural and chemical/mineralogical changes in the pore space affect the way water will adsorb and expel oil from the rock [3,8,11-17]. Previous research on fluid 
injection has been carried out $[5,8,17-21]$, and three ions have been proven to play important roles when chalk is exposed to seawater at elevated temperatures: $\mathrm{Ca}^{2+}, \mathrm{Mg}^{2+}$, and $\mathrm{SO}_{4}{ }^{2-}$. The injected seawater triggers several mechanisms such as precipitation, dissolution, ion exchange, adsorption, and desorption, to interplay at the same time, with different relative significance depending on the position in the reservoir (nearby to the injector or to the producer). It is therefore beneficial to simplify the system and study each ion individually. With $\mathrm{MgCl}_{2}$ brines, which represent simplified aqueous chemistry of seawater, the role of $\mathrm{Mg}^{2+}$ is specifically studied.

The two cores investigated in this study (see Figure 1) were flooded with $\mathrm{MgCl}_{2}$ for 1.5 (Long Term Test, LTT) and 3 years (Ultra Long Term Test, ULTT) under reservoir conditions (LTT: $130^{\circ} \mathrm{C}, 1 \mathrm{PV} /$ day, 9.3 MPa effective stress, ULTT: $130^{\circ} \mathrm{C}$, varying between 1-3 PV/day, 10.4 MPa effective stress), in order to reach a mineralogical insight of the basic processes that happen during long time brine injection.

The analyses are carried out by Raman spectroscopy, which is a quick and versatile technique gaining a wide range of information; it can easily be applied to almost all substances (gases, liquids, solids, organic, and inorganic), with only the exception of metals. In the last decades, Raman spectroscopy has proven to be an easy way to obtain mineral identification (see Figure 2) [22-27], as every Raman spectrum is like a fingerprint that can provide various types of information such as crystallinity, phase, intrinsic stress/strain, and polymorphism [28-31]. Furthermore, mineral phases can be identified down to a few microns [32], a possibility of paramount importance in chalk investigation. By applying Raman to flooded chalk, a "grain by grain" methodology was developed to obtain a better understanding of its mineralogy.

\section{Materials and Methods}

\subsection{Samples}

The samples studied in this project are all chalk, fine-grained carbonate rocks, built primarily of the skeletal debris of micro- and nano-organisms, mainly coccoliths, shed from coccolithophores (see SEM images in Figure 3). The cores were sampled at the Lixhe outcrop (Gulpen Formation, Campanian to late early Maastrichtian) [33] near Liège in Belgium, in particular from the Zeven Wegen Member [34] with an age of 75.5-78.0 Ma. The chalk shows clear signs of recrystallization, contact cements, and particle interlocking. Nevertheless, coccoliths are still well preserved, and the rock presents intrafossil porosity [35]. The chalk from Liège shows a clean compositional nature, as the main mineral component is calcite $\left(\mathrm{CaCO}_{3}\right)$, together with minor abundances of non-carbonate material (between $3 \mathrm{wt} \%$ and $5 \mathrm{wt} \%$ in total) $[21,36]$ that mainly consist of quartz, smectite/mixed smectite-illite layer, mica, kaolinite, and clinoptilolite, and minor amounts of zeolite, apatite, opal, feldspar, pyroxene, pyrites, and titanium oxide [36,37].

The porosities lie in the range of $40-45 \%$ [12,21,33,35,38,39]. More information about mineralogy, petrography, and rheological characteristics of these chalk successions can be found in literature $[12,33,35,38,39]$. Onshore chalk successions are used as analogues for North Sea reservoir chalk in several studies $[8,17,20,21,35]$.

\subsection{Flooding Experiments}

For this study, an unflooded chalk core and two long-term tests (length: $\sim 70 \mathrm{~mm}$, diameter: $\sim 38 \mathrm{~mm}$ ) were analyzed. Both test cores were flooded with $\mathrm{MgCl}_{2}$ in reservoir conditions and mounted into triaxial cells that allow for measurements of axial strains while flooding of reactive fluids at elevated pressures, stresses, and temperatures. Each triaxial cell was equipped with a heating jacket and a regulation system that kept the temperature constant at $130 \pm 0.1^{\circ} \mathrm{C}$ throughout the experiment. To avoid boiling at temperatures above $100{ }^{\circ} \mathrm{C}$, a pore pressure of $0.7 \mathrm{MPa}$ was applied prior to the heating of the system. While distilled water was injected to ensure a clean pore system and to clean the sample, the confining pressure and pore pressure were simultaneously increased from 0.5 and $0 \mathrm{MPa}$ to 1.2 and $0.7 \mathrm{MPa}$, respectively, with a constant effective stress equal to $0.5 \mathrm{MPa}$. Then, the confining 
pressure was increased to 10.0 MPa (LTT) and 11.1 MPa (ULTT). A $0.219 \mathrm{M} \mathrm{MgCl}_{2}$ brine, which has an ionic strength similar to that of seawater, was injected with a flooding rate of 1 pore volume per day (PV/day) for the LTT and varying between 1-3 PV/day for the ULTT. The effective stress was 9.3 MPa and 10.4 MPa for the LTT and the ULTT, respectively. After the experiment was finished, the two flooded cores were cleaned at $130{ }^{\circ} \mathrm{C}$ by injecting a minimum of three pore volumes of distilled water, without affecting the mineralogy of the samples. For more information about flooding experiment and cleaning procedure refer to Madland et al., 2011 [8]. After drying, the two test cores were cut into slices with thicknesses of about $10 \mathrm{~mm}$ (LTT; to the left in Figure 1) and of about $35 \mathrm{~mm}$ (ULTT; to the right in Figure 1); the samples were then investigated with different methods. For a thorough description of the performed tests, the reader is referred to Zimmermann et al., 2015 [36] for the LTT and Nermoen et al., 2015 [40] for the ULTT, since a detailed report on the experiments would have been out of focus in this mineralogical study.

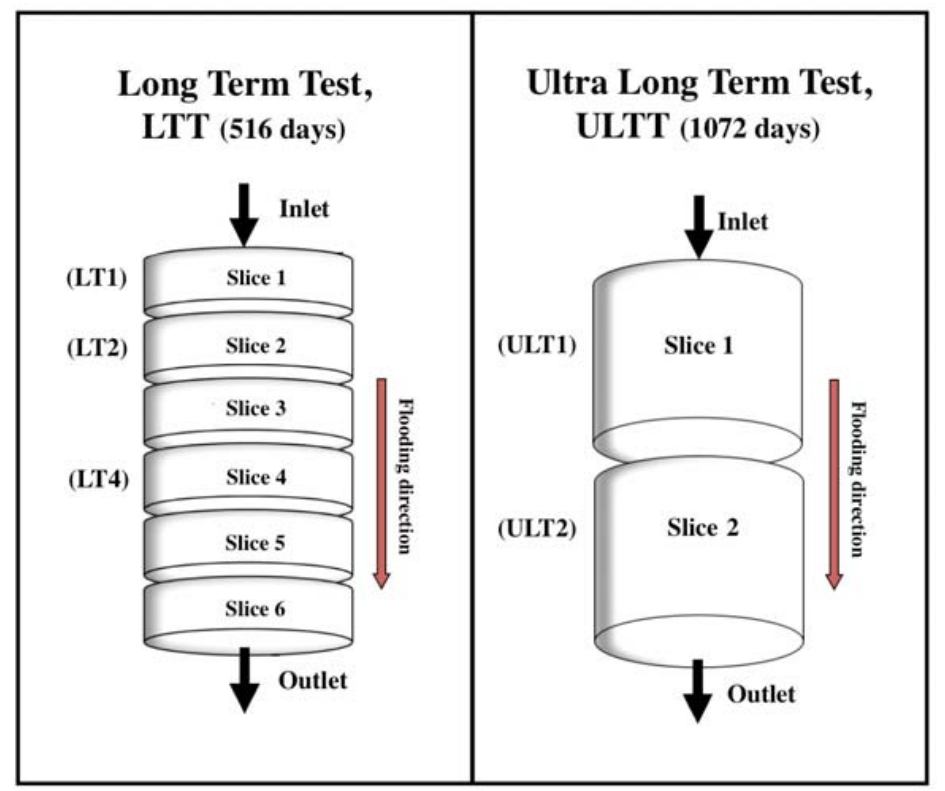

Figure 1. Schematic drawings of how the two cores were cut after the flooding experiment: Long Term Test (LTT) to the left (modified from Zimmermann et al., 2015 [36]) and Ultra Long Term Test to the right.

\subsection{Field Emission Gun-Scanning Electron Microscopy with Energy-Dispersive Spectroscopy}

Field Emission Gun-Scanning Electron Microscopy with Energy-Dispersive Spectroscopy (FEG-SEM) analyses were performed at the University of Stavanger using a Zeiss Supra VP 35. Freshly chipped off pieces of slices from the two core samples were analyzed together with chips of unflooded chalk from the end-pieces of the same cores. The samples were coated with palladium, ensuring a steady flux of electrons. The microscope parameters were set at an acceleration voltage between 12 to $15 \mathrm{kV}, 30 \mu \mathrm{m}$ aperture, and a working distance between 10 and $12 \mathrm{~mm}$. The high current setting was used. To perform qualitative and semi-quantitative analyses of the chemical composition of the imaged areas, an EDAX energy dispersive X-ray spectroscopy (EDS) system was used. To optimize the quantification results, and because the chalk predominantly consists of calcite, an Iceland spar calcite crystal was used to calibrate the system [36].

\subsection{Raman Spectroscopy}

During this study, most of the spectra (465 of 557; reported with " $\mathrm{H}^{\prime}$ in Figure 2) were collected with a Horiba XploRA Raman spectrometer (Kyoto, Japan) equipped with an Olympus microscope (Tokyo, Japan) with maximum magnification of $100 \times$, and a motorized $x-y$ stage. Calibration of 
spectra was obtained using a silicon wafer with a main peak at $520.7 \mathrm{~cm}^{-1}$ as reference and maintained during the analysis with a constant checking of the position of a sharp neon lamp emission line at $476.8 \mathrm{~cm}^{-1}$. Other spectra (92 of 557; LTT slice 1: p1_G and I; p2_D and E; slice 4: C and D; reported with " $R$ " in Figure 2) were obtained using a high-resolution Renishaw inVia Reflex confocal Raman microscope, equipped with a Leica DM2500 polarizing microscope (Wetzlar, Germany) (maximum magnification of $100 \times$ ) and motorized $x-y$ stages. With both spectrometers, spectra were collected with a $532 \mathrm{~nm}$ line, solid-state lasers (10 $\mathrm{mW}$ at the sample); laser spot; and $\mathrm{x}, \mathrm{y}, \mathrm{z}$ spatial resolution around $1 \mu \mathrm{m}$ with $100 \times$ enlargement, spectral resolution of $\pm 1 \mathrm{~cm}^{-1}$, and acquisition time of 1-2 min. Microscope pictures were taken for each beamed grain or cluster of grains. The spectral region found to be the most important and convenient to our study was the low-medium one; setting the XploRA spectrometer with a 2400 lines/mm grating in back-scattering configuration allowed us to collect in the spectral range 100-1200 $\mathrm{cm}^{-1}$. Using a grating of 1800 lines $/ \mathrm{mm}$ with the inVia spectrometer instead allowed us to collect in the range of 140-1900 $\mathrm{cm}^{-1}$. In order to try to detect the occurrence of hydrated silicates, the region between 2900 and $4200 \mathrm{~cm}^{-1}$ was investigated, collecting 200 spectra with the Renishaw inVia Reflex confocal Raman microscope at $100 \times$ of magnification.

Determination of the position of the peaks was performed through the Gaussian-Lorentzian (Pseudo Voight) deconvolution method, with an accuracy of $0.2 \mathrm{~cm}^{-1}$, using the software Labspec 5, utilized also for baseline subtraction that helped to eliminate the occasional fluorescence and background noise. Chalk cores were not analyzed directly on the rock surface, which can be done if the importance of the sample requires it. A very small amount of powder was scraped off with a needle from the rock, and placed and spread on a glass slide. In this way, it was possible to better focus on the sub-micrometric grains, and to obtain a consequent enhancement of the Raman signal. No specific preparation is needed to perform these analyses. The procedure allows for further investigation with other instrumentation on the rock sample (since there is no visible alteration after the scraping) or on the very same grains placed on the glass slide, which were not be destroyed during the Raman analysis.

\subsection{Raman Spectroscopy on Carbonates}

For their large diffusion and good Raman signal, carbonates have been investigated in detail, with particular attention to thermodynamic properties and their vibrational spectra $[23,25,41-46]$. Their Raman peaks positions are influenced by the magnesium content and crystallographic structure, and allow one to distinguish calcite from Mg-calcite, aragonite, magnesite, huntite, dolomite, and hydrated magnesium carbonates (such as artinite, nesquehonite, and hydromagnesite) [32,42,44,46-48]. Carbonate minerals show comparable spectra, as their structure is quite similar; a consistent increase in Raman shifts according to their Mg content occurs between calcite and magnesite, as a consequence of increased inter-atomic distances following the substitution of $\mathrm{Ca}^{2+}$ with the smaller $\mathrm{Mg}^{2+}$ ion in the cell $[23,42,49]$. This shift assists in distinguishing between the different carbonates.

Carbonate group minerals spectra (see Figure 2) present four main peaks, which can be divided into internal vibrations of the $\left(\mathrm{CO}_{3}\right)^{2-}$ group (symmetric stretching, $600-1200 \mathrm{~cm}^{-1}$, and asymmetric stretching, $\left.1200-1700 \mathrm{~cm}^{-1}\right)[38,42,48,50,51]$ and into lattice vibrations involving translation and librations of the $\left(\mathrm{CO}_{3}\right)^{2-}$ group relative to the $\mathrm{Ca}^{2+}$ or $\mathrm{Mg}^{2+}$ ions $\left(100-500 \mathrm{~cm}^{-1}\right)$. The strongest and sharpest peak $\left(v_{1}\right.$, symmetric stretching mode of the carbonate ion) is present around $1086-1095 \mathrm{~cm}^{-1}$ (calcite-magnesite, respectively), along with other subsidiary bands at $150-215 \mathrm{~cm}^{-1}$ ( $\mathrm{T}$, translational mode), 280-330 $\mathrm{cm}^{-1}$ (L, librational mode), and $712-738 \mathrm{~cm}^{-1}\left(v_{4}\right.$, in-plane bending of the $\left(\mathrm{CO}_{3}\right)^{2-}$ group) $[28,42,52]$. 


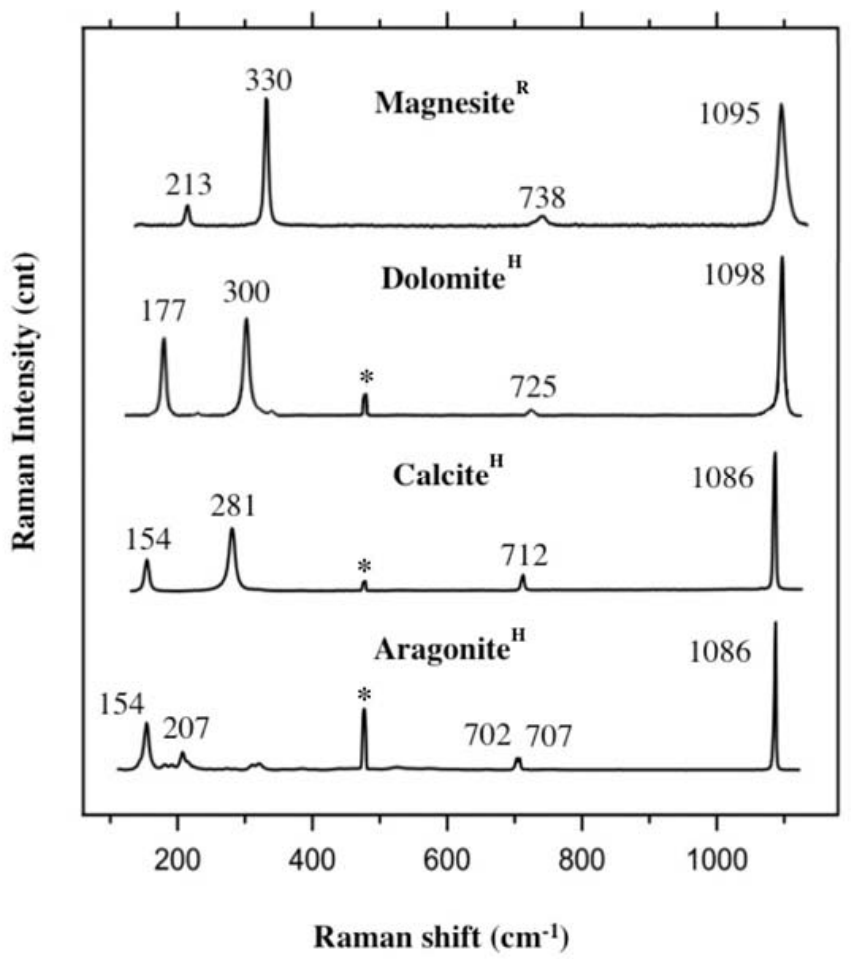

Figure 2. Raman spectra of calcium and magnesium carbonates: magnesite (Micro-Analysis Consultants certificated standard), dolomite (UNIMIB standard sample, Selvino, Italy), calcite (UNIMIB standard sample, Chihuahua, Mexico, $\sim 0 \mathrm{~mol} \% \mathrm{MgCO}_{3}$ ), and aragonite (UNIMIB—University of Milano Bicocca-standard sample, Val Formazza, Italy). Spectra with " $\mathrm{R}$ " were analyzed by the Renishaw inVia confocal Raman microscope and spectra with " $\mathrm{H}$ " by Horiba Xplora. Stars represent the neon lamp emission line at $476.8 \mathrm{~cm}^{-1}$ used for calibration with the Horiba XploRA spectrometer. Peak positions are reported without decimals.

\subsection{Earlier Studies and Characterisation of the Sample Material}

Various high-resolution methods were used to study mineralogical alteration in flooded chalk: field emission gun scanning electron microscopy, energy-dispersive $\mathrm{X}$-ray spectroscopy (FEG-SEM-EDS) $[3,5,8,14,36,37,53]$, nano secondary ion mass spectrometry (NanoSIMS) [36,47,54], X-ray diffraction (XRD) [36], whole-rock geochemistry techniques [21,36]. Tip-Enhanced Raman Spectroscopy-Atomic Force Microscopy (TERS-AFM) [55,56], Transmission Electron Microscopy (TEM) [53,57], and Mineral Liberation Analysis (MLA) [53]. The authors (Zimmermann et al., 2015 for the LTT, and Nermoen et al., 2015 for the ULTT) determined a loss of $\mathrm{Ca}^{2+}$ and a gain in $\mathrm{Mg}^{2+}$, demonstrating a precipitation of new Mg-minerals in the core. FEG-SEM and TEM images have shown magnesite crystals with a grain size between $100 \mathrm{~nm}$ and $1 \mu \mathrm{m}[53,57]$.

Based on geochemical methods, Zimmermann et al., 2015 [36] could calculate that $20 \%$ of the mass of the core had been dissolved during a 1.5 years long experiment. The core experienced axial shortening of $18 \%$ (in length) and a porosity reduction of $20 \%$.

In the Long Term Test (LTT), using X-ray diffraction (XRD) [36], one could detect the presence of magnesite, chrysotile (slice 1-3), tilleiyte (only in slice 4), quartz, and anthophyllite, as well as gypsum (the latter only in the unflooded chalk). Following a geochemical model [14], talc should precipitate, but this mineral could not be detected by XRD. Furthermore, magnesite could only be detected when it was rather abundant, and showed the limits of XRD as a detection method for traces of minerals. NanoSIMS 50 was the only analytical method that could detect positively with an image proof magnesite and very tiny new grown quartz of micron- and sub-micron sizes [36]. When analyzed by MLA, the shorter of the two tests, LTT, displayed a rather sharp $(\sim 1.5 \mathrm{~mm})$ transition between two 
areas with different mineralogy [53]. Closest to the inlet of the core, the rock material is completely altered into magnesite with minor contents of calcium along with clay minerals. In the area furthest away from the inlet, the mineralogy is still dominated by calcite, with occurrences of magnesite and clay, indicating only partial dissolution of calcite and precipitation of magnesite opposed to the complete substitution at the inlet. In the ULTT, the whole core showed similar composition, magnesite with the mentioned calcium impurities, and clay.

Nermoen et al. 2015 [40] describes the flooding experiment of the three years test (ULTT) in detail, and documents how dissolution and precipitation of the solid volume may alter significantly the porosity and permeability evolution during compaction.

The solid density increased from 2.68 to $2.90 \mathrm{~g} / \mathrm{cm}^{3}$ throughout the experiment; simultaneously, the core has lost $22.93 \mathrm{~g}$, which exemplifies that solid volume changes occur during flooding of $\mathrm{MgCl}_{2}$ brines.

It is common for the two tests that compaction alone cannot explain the changes in permeability and porosity over time. For the ULTT [40], the permeability and calculated porosity are lowered during the start of the experiment in which compaction is the controlling mechanism, while throughout the experiment, the permeability and porosity starts to increase again. This is believed to be caused by processes that involve mineralogical transformation through dissolution of primary and precipitation of secondary minerals. These changes in mineralogy are therefore an important factor for both qualifying and quantifying to understand geomechanical alteration, as also seen in Wang et al., 2016 [21].

\section{Results}

\subsection{FEG-SEM-EDS}

The composition of the two cores after flooding has been affected by the nature of the fluid flow paths. This is often only visible at microscale, has a specific geometric form, and is composed of several compositional trends [53], and therefore awaits a detailed study and is not of relevance here. Hence, a quick and thorough investigation of the mineralogical composition prior to detailed FEG-SEM-EDS studies or further meticulous electron- and ion-beam-based analyses would be helpful.

When studied by FEG-SEM-EDS, both the texture and the chemical composition of the chalk is significantly altered compared to the unflooded material (Figure 3). The newly precipitated crystals are found in massive parts of the core (inlet part), with a homogenous high-magnesium carbonate composition, as well as single crystals within the calcite dominated areas. The grains are no longer rounded, but show a rhombic crystal shape, with grain-size mostly below $1 \mu \mathrm{m}$. In the completely altered areas, coccoliths and other micro/nano-fossils are no longer observed, while in parts where the calcite is still present, clear signs of dissolution is visible [36,53]. Additionally, significant amounts of clay-minerals are present, with main constituents being $\mathrm{Mg}$ and $\mathrm{Si}$, which could be interpreted to be talc.

LTT
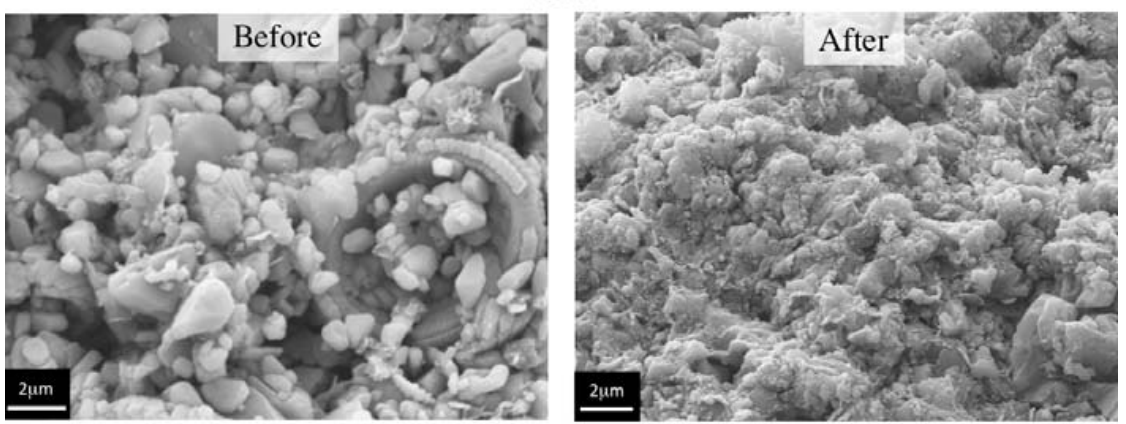

Figure 3. Cont. 


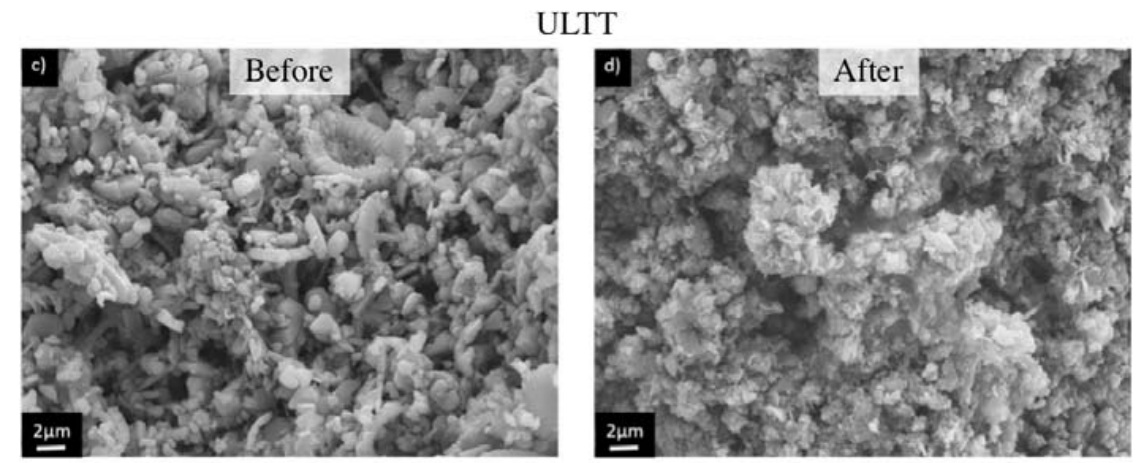

Figure 3. (a) SEM-micrograph of the LTT core before flooding; main components are coccoliths and fragments with a calcitic composition. (b) SEM-micrograph of the altered slice 4 of the LTT core after flooding with $\mathrm{MgCl}_{2}$; coccoliths and other fossils are no longer visible, only magnesite crystals mainly below $1 \mu \mathrm{m}$ in size are present. (c) SEM-micrograph of unflooded chalk of the ULTT with main components as observed in (a). (d) SEM-micrograph from slice 2 close to the outlet of the core, after $\mathrm{MgCl}_{2}$ flooding; a deep and pervasive secondary growth of sub-micrometric and rombic magnesite crystals is visible.

\subsection{Raman Spectroscopy}

\subsubsection{Generals}

Raman spectroscopy has proven to be easy to use, but it requires an experienced operator to decide the setting of the instrument and how to interpret the spectra (see below). The mineralogical changes due to fluid injection were quickly evaluated: in few tens of seconds it was possible to distinguish the carbonate minerals present in the chalk (see Table 1). 664 spectra were collected on an unflooded Liège chalk sample, on LTT and ULTT; only 5 could not be identified, as they were not present in databases or literature. In LTT core, 557 low region spectra were collected, 226 in slice 1 (120 in fragment 1 , LT1_p1; 106 in fragment 2, LT1_p2), 220 in slice 2 (LT2), and 111 in slice 4 (LT4). In ULTT, 90 spectra were collected in 9 different areas of the core. Raman analyses were carried out in locations where previous studies have shown a change in composition or a change in color of the sample, which might indicate precipitation.

Calcite was the only mineral detected in the unflooded Liège chalk sample (Figure 4). In both ULTT and LTT cores, calcite and magnesite were present but no dolomite, aragonite, huntite, high magnesium-calcite, or hydrated minerals such as artinite, nesquehonite, and hydromagnesite were detected. As calcite Raman peaks positions reflect the magnesium content present in its lattice [46], it is possible to determine that the calcites present in ULTT and LTT always contain a low magnesium content $(0-10 \mathrm{~mol} \% \approx 4 \mathrm{wt} \%$; [46]) in the mineral.

Table 1. Mineral composition of the two cores: amounts and percentages of Raman spectra collected for each mineral in the Long Term Test (LTT) and in the Ultra Long Term Test (ULTT). When a two minerals spectrum was found, both components were counted to obtain the calcite/magnesite percentages. For sample identification, see Figures 7 and 10.

\begin{tabular}{|c|c|c|c|c|c|c|c|c|}
\hline & \multicolumn{2}{|c|}{ Calcite } & \multicolumn{2}{|c|}{ Magnesite } & \multicolumn{2}{|c|}{ Unknown } & \multicolumn{2}{|c|}{ Other } \\
\hline & Spectra & $\%$ & Spectra & $\%$ & Spectra & $\%$ & Spectra & $\%$ \\
\hline LT1_p1A & 20 & $77 \%$ & 6 & $23 \%$ & & & & \\
\hline LT1_p1B & 3 & $13 \%$ & 20 & $87 \%$ & & & & \\
\hline LT1_p1C & 20 & $87 \%$ & 3 & $13 \%$ & & & & \\
\hline LT1_p1D & 10 & $31 \%$ & 19 & $63 \%$ & 2 & $6 \%$ & & \\
\hline LT1_p1E & 7 & $26 \%$ & 20 & $74 \%$ & & & & \\
\hline LT1_p1F & 18 & $60 \%$ & 12 & $40 \%$ & & & & \\
\hline LT1_p1G & 0 & $0 \%$ & 25 & $100 \%$ & & & 1 Brookite & $4 \%$ \\
\hline LT1_p1H & 0 & $0 \%$ & 25 & $100 \%$ & & & & \\
\hline
\end{tabular}


Table 1. Cont.

\begin{tabular}{ccccccccc}
\hline & \multicolumn{2}{c}{ Calcite } & \multicolumn{2}{c}{ Magnesite } & \multicolumn{2}{c}{ Unknown } & \multicolumn{2}{c}{ Other } \\
\cline { 2 - 8 } & Spectra & $\%$ & Spectra & $\%$ & Spectra & $\%$ & Spectra & $\%$ \\
\hline LT1_p1I & 0 & $0 \%$ & 25 & $100 \%$ & & & & \\
LT1_p2A & 18 & $82 \%$ & 4 & $18 \%$ & & & \\
LT1_p2B & 2 & $10 \%$ & 18 & $90 \%$ & & & \\
LT1_p2C & 13 & $39 \%$ & 20 & $61 \%$ & & & \\
LT1_p2D & 16 & $53 \%$ & 14 & $47 \%$ & & & \\
LT1_p2E & 4 & $82 \%$ & 16 & $18 \%$ & & & \\
LT2_A & 70 & $92 \%$ & 6 & $8 \%$ & & & \\
LT2_B & 49 & $86 \%$ & 7 & $12 \%$ & 1 & $2 \%$ & & \\
LT2_C & 48 & $61 \%$ & 31 & $39 \%$ & & & \\
LT2_D & 30 & $41 \%$ & 43 & $58 \%$ & & & \\
LT4_A & 19 & $79 \%$ & 5 & $21 \%$ & & & \\
LT4_B & 18 & $69 \%$ & 6 & $23 \%$ & 2 & $8 \%$ & \\
LT4_C & 20 & $100 \%$ & 0 & $0 \%$ & & & \\
LT4_D & 20 & $100 \%$ & 0 & $0 \%$ & & & \\
ULT1_1 & 1 & $9 \%$ & 10 & $91 \%$ & 1 & & \\
ULT2_4 & 1 & $9 \%$ & 10 & $91 \%$ & & & \\
ULT2_5 & 0 & $0 \%$ & 10 & $100 \%$ & & & \\
ULT2_5B & 1 & $9 \%$ & 10 & $91 \%$ & & & \\
ULT2_6 & 1 & $9 \%$ & 10 & $91 \%$ & & & \\
ULT2_7 & 2 & $17 \%$ & 10 & $83 \%$ & & & \\
ULT2_8 & 1 & $9 \%$ & 10 & $91 \%$ & & & \\
ULT1_9 & 0 & $0 \%$ & 10 & $100 \%$ & & & \\
ULT1_10 & 1 & $9 \%$ & 10 & $91 \%$ & 3 & & \\
\hline
\end{tabular}

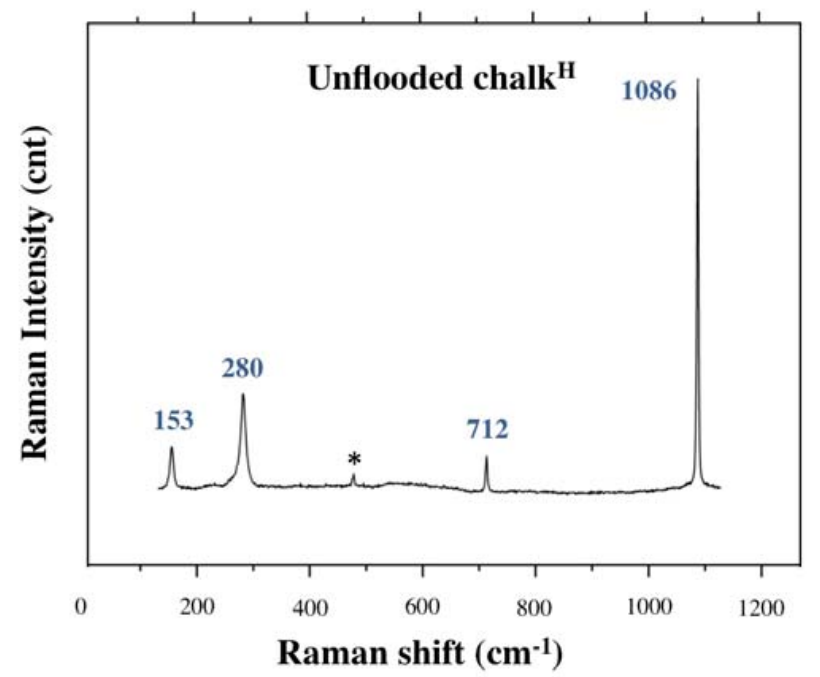

Figure 4. Raman spectrum collected on an unflooded Liège chalk core. Calcite is the only mineral detected, and its peaks are reported in blue/bold. The spectrum was collected with the Horiba XploRA spectrometer; the star represents the neon lamp emission line at $476.8 \mathrm{~cm}^{-1}$ used for calibration with the Horiba XploRA spectrometer. Peak positions are reported without decimals.

An important issue regarding the results presented in this study (Table 1) that are shown as a percentage mineral/total is that we need to consider these $\%$ not as weight $\%$ or volume $\%$, as the data express the presence of the signal of a mineral compared to the total of the collected spectra. When vibrational modes of both calcite and magnesite were detected simultaneously in one spectrum, both minerals were counted. In fact, occasionally, peaks of both calcite and magnesite were present in the same spectrum: this can happen when the analyses are performed on overlapped or very closely spaced fine grains (dimension of 1-2 $\mu \mathrm{m}$ ), when the laser beams both grains at the same time and the laser diameter is too large. In this case, the detector collects photons scattered from the two minerals, resulting in a spectrum that is the mathematical sum of the two spectra of the two minerals 
(see Figure 5). Consequently, the strong and sharp $v_{1}$ peak (symmetric stretching mode of the carbonate ion) of both calcite and magnesite is present in one spectrum, respectively, around 1086 and around $1095 \mathrm{~cm}^{-1}[25,44,45,48]$, depending on the intensity, sharpness, and nearness of these two peaks; shoulders (asymmetric peaks) or double peaks (peaks with two edges) can be present (examples in Figure 5). However, of importance is the fact that this can be detected. Another clear result of the simultaneous presence of calcite and magnesite signals in the same spectrum is given by the occurrence of the L (librational mode) peaks of the two carbonates at 280 and $330 \mathrm{~cm}^{-1}$, respectively. When a two mineral spectrum was found, both components were counted to obtain the calcite/magnesite percentages for each slice (see Table 1). It is important to point out that, as Raman spectroscopy can differentiate between the carbonate species, the spectrum collected in cases such as the one described above (a magnesite and a calcite beamed at the same time, resulting in a combined spectrum) would be different from high Mg-calcite [46] or a dolomite spectrum (compare spectra shown in Figure 2 and the ones presented in Figure 5).

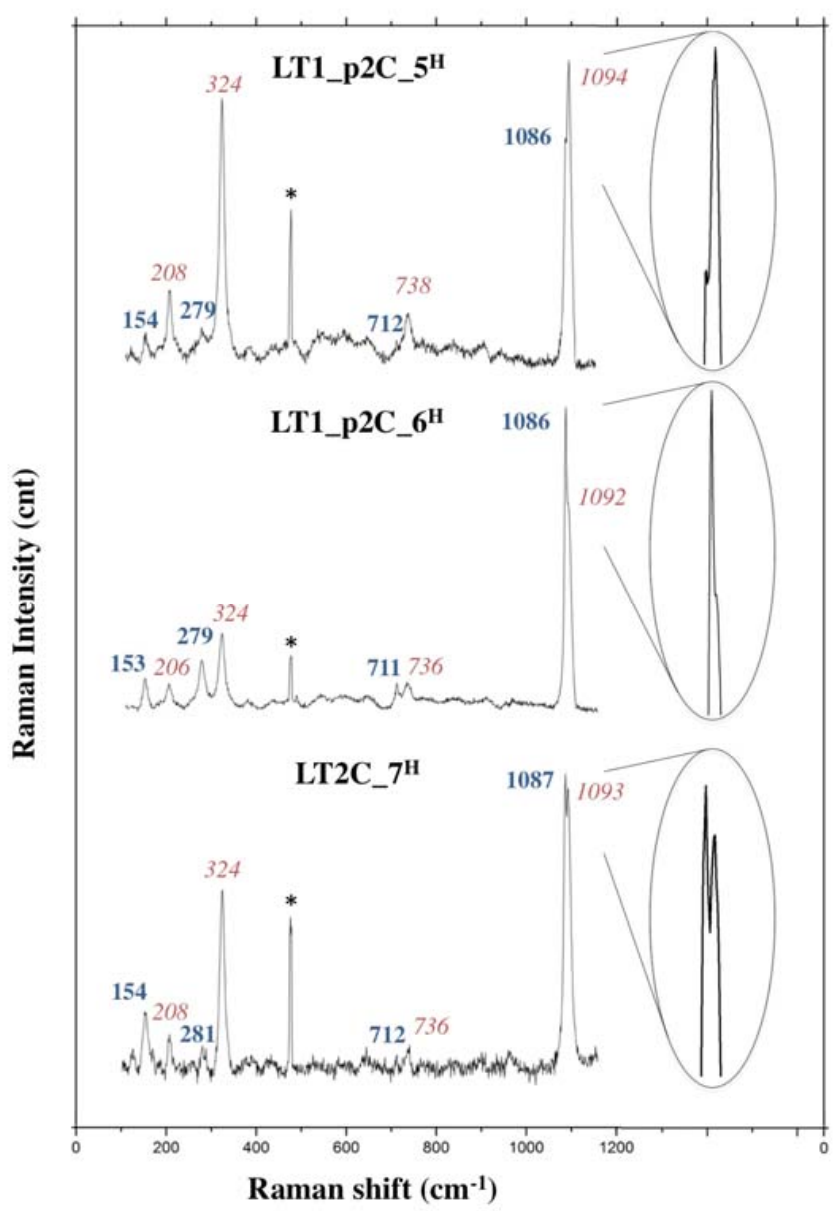

Figure 5. Raman spectra showing magnesite and calcite peaks in the same spectrum. This happen when grains of $1-2 \mu \mathrm{m}$ in size and different mineralogy are overlapped or placed very close: the laser beams both grains at the same time, and, as a consequence, the instrumentation detects the vibrational modes of both minerals. In LT1_p2C_5, the signal from magnesite is stronger than the calcite one; in LT1_p2C_6 it is weaker. The main peaks $\left(v^{1}\right.$, symmetric stretching mode of the carbonate ion) of the two minerals are very close, generating a high peak with a "shoulder". In the third example shown, LT2C_7, the $v_{1}$ of the two grains is so sharp and strong that a double peak is present. Calcite peaks are reported in blue/bold, magnesite peaks in red/italic. All the spectra were collected with the Horiba XploRA spectrometer; stars represent the neon lamp emission line at $476.8 \mathrm{~cm}^{-1}$ used for calibration. Peak positions are reported without decimals. 
In order to detect the occurrence of hydrated silicates, the presence of diagnostic vibrational modes in the high frequencies region $\left(2900-4200 \mathrm{~cm}^{-1}\right)$ of the Raman spectra was used, where the $(\mathrm{OH})^{-}$vibrational modes are located $[25,58,59]$. The signal of phyllosilicates is quite weak and, in the $0-1200 \mathrm{~cm}^{-1}$ region, it is easily covered by the calcite and magnesite stronger intensity. As these two carbonates are anhydrous, they do not show peaks in the high region of the spectra. More than 200 high region spectra were collected in slice one, LT1_p2_B, where an intense recrystallization of magnesite was already registered by Raman spectroscopy. The platy and very thin habit of phyllosilicates and clay minerals makes them really challenging to be detected, as it is very difficult to focus the laser inside their crystals and distinguish their weak scattering. Also, camera resolution and laser wavelength limit the analysis, and can lower the capability of focusing on the sample surface (under 1-2 $\mu \mathrm{m}$ in size).

\subsubsection{Long Term Test}

Raman spectroscopy could identify the presence of recrystallized magnesite along the core of the Long Term Test up to $4 \mathrm{~cm}$ from the injection surface (see Figures $5-7$ ), which is also supported by Zimmermann et al., 2015 [36]. As predictable, the average alteration of the core is more pervasive close to the inlet surface, showing a decreasing amount of newly grown minerals with flooding direction (60\% of magnesite in slice 1-LT1, 30\% in in slice 2-LT2, and 10\% in slice 4-LT4; see Table 1 and Figure 7). In Zimmermann et al., 2015 [36] positive XRD proof for magnesite could not be given in slice 4; however, geochemical data highlighted ca. 3.9\% of $\mathrm{MgO}$ present in this slice, in comparison to $0.3 \%$ of $\mathrm{MgO}$ in the unflooded material. In this study, only two non-carbonate crystals out of 664 Raman spectra were detected in LTT: brookite in LT1_p1_G and rutile in LT2_D (see Table 1 and Figure 8).

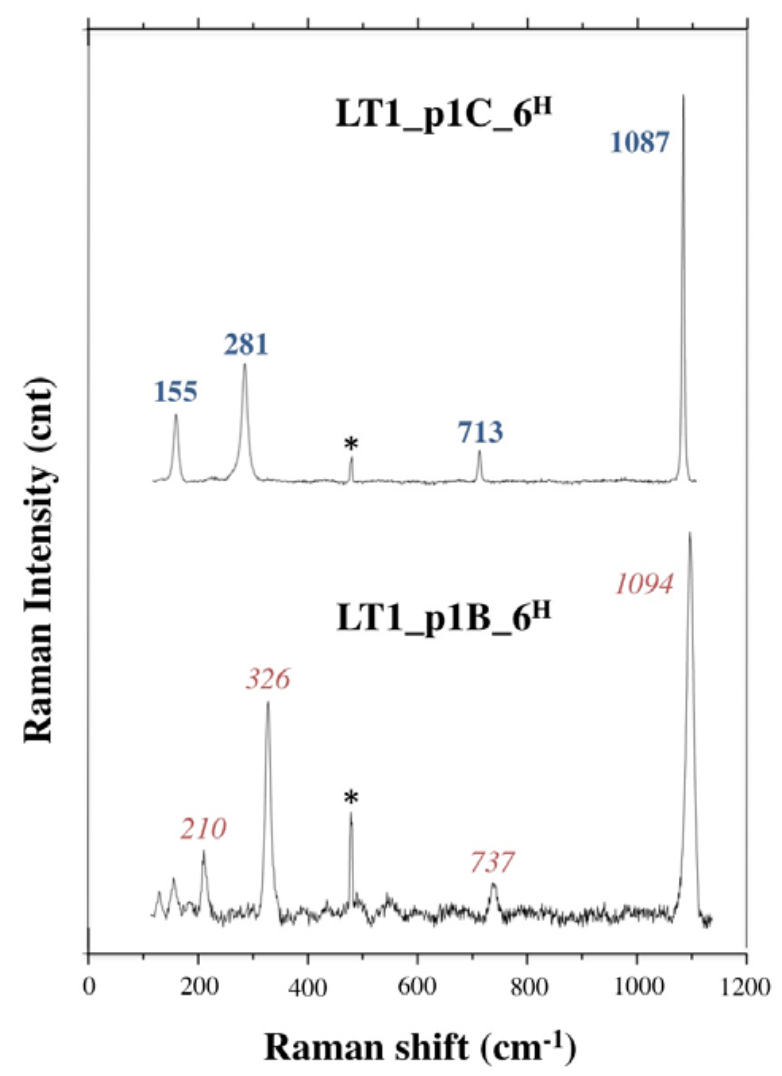

Figure 6. Raman spectra collected on the first slice of the Long Term Test. Raman showing the occurrence of the original calcite (LT1_p1C_6) and the presence of recrystallized magnesite (LT1_p1B_6). Calcite peaks are reported in blue/bold, magnesite peaks in red/italic. All the spectra were collected with the Horiba XploRA spectrometer; stars represent the neon lamp emission line at $476.8 \mathrm{~cm}^{-1}$ used for calibration with the Horiba XploRA spectrometer. Peak positions are reported without decimals. 


\section{Long Term Test}

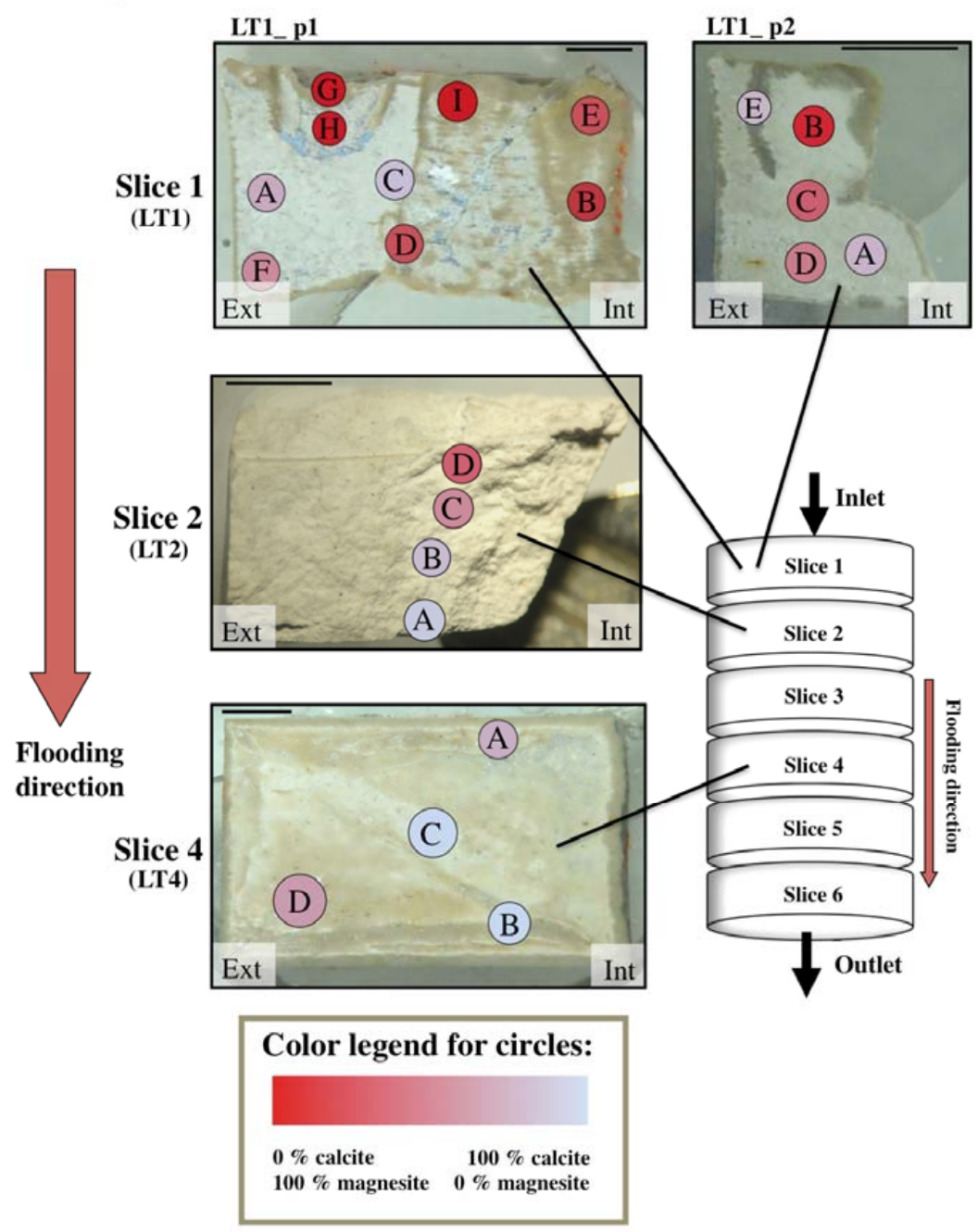

Figure 7. Mineralogical composition of the LTT core: 10 to 70 spectra have been collected in each of the area shown (9 areas in LT1_p1, 4 in LT1_p2, 4 in LT2, and 4 in LT4). Color legend reflects the percentage of calcite and magnesite spectra collected in each area of the sample. See Table 1 for calcite and magnesite amounts and percentages obtained for each area. Flooding direction is indicated. Inner (core) end external (rim), parts of the samples are marked. The scales represent $0.25 \mathrm{~cm}$. A schematic drawing (modified from Zimmermann et al., 2015 [36]) of how the cores were cut after the flooding experiment is shown to the right.

Two pieces of Slice 1 (LT1_p1 and LT1_p2, LTT; see Figure 7) were analyzed, with a total of 14 areas, and 226 Raman spectra (Table 1; Figures 6 and 7).

In fragment 1 (LT1_p1), intense magnesite regrowth is present in the inner portion of the core (LT1_p1 E and B 74, and 87\%, respectively, see Table 1 and Figure 7), which becomes less pervasive close to the external rims (LT1_p1 A, F: 23, 40\%,respectively). In LT1_p1, a brown/ocre flow semi-circular structure is present and clearly visible to naked eye in the external part of the core; here, a complete recrystallization to magnesite is present, reaching 100\% (LT1_p1 G and H, see Figure 7). However, in this region, also a crystal of brookite $\left(\mathrm{TiO}_{2}\right)$ was detected (see Table 1 and Figure 8). The average recrystallization of LT1_p2 is $47 \%$, and another textural element has been observed, a grey vein of calcite $\left(\mathrm{CaCO}_{3} 82 \%\right.$, LT1_p2 E, see Figure 7). In order to try to detect hydrated minerals in LT1_p2, 210 high region spectra were collected. Unfortunately, no signal of clay minerals or talc was registered in any of them. 
In Slice 2 (LT2; LTT), a longitudinal gradient in Mg content is perfectly detectable along flooding direction with a major magnesite recrystallization in the nearest areas to the inlet surface (from 58 (in LT2_D) to 8 (in LT2_A) \%, see Table 1 and Figure 7). Four areas were investigated in slice 2, with a total amount of 220 Raman spectra. A rutile spectrum was collected in LT2_D (see Table 1 and Figure 8).

In Slice 4 (LT4; LTT), the recrystallization is less pervasive in the core than in the others (LT1 and LT2, LTT), as is the furthest from the inlet surface (Table 1; Figure 7). A diagonal deep and pale grey structure crosses the LT4 slice (see Figure 7) with a pure calcitic composition (111 spectra, 100\% of $\mathrm{CaCO}_{3}$ no magnesite spectra were detected in this area). Some $\mathrm{MgCO}_{3}$ spectra have been collected in a brownish area near the rim of the core (23\% of magnesite).

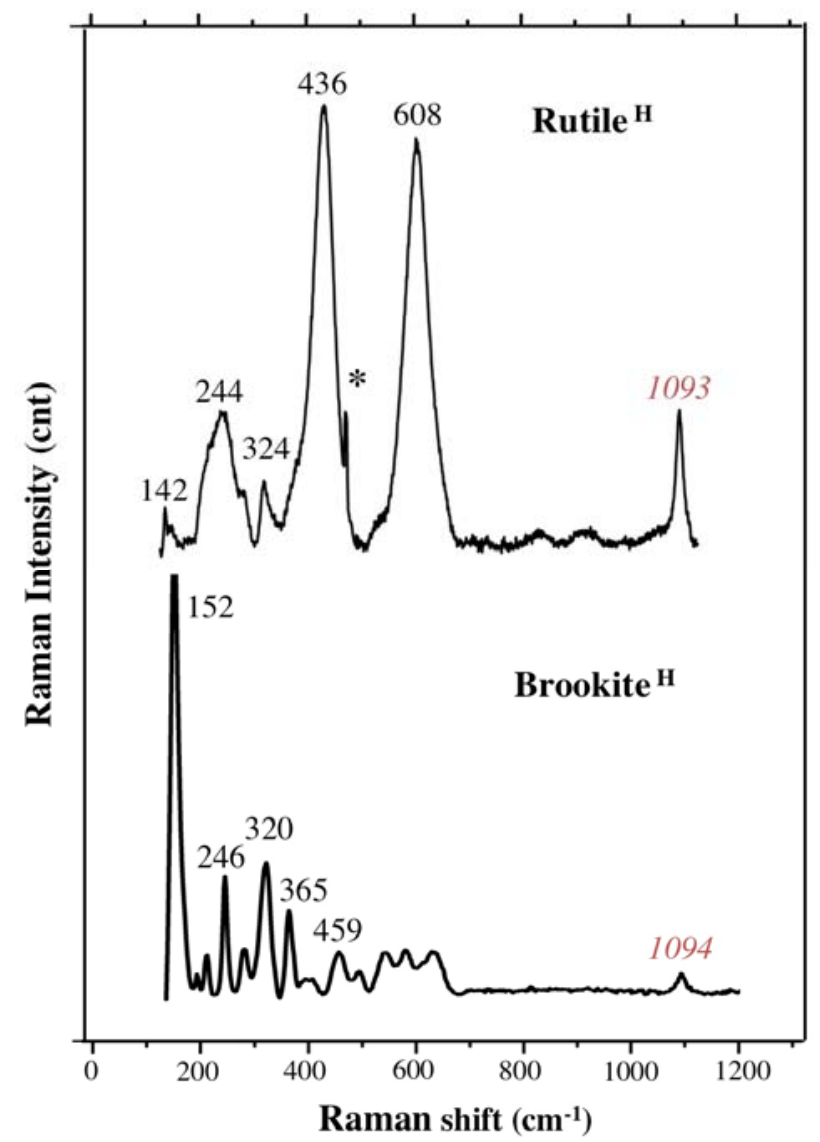

Figure 8. A brookite spectrum (identified in LT1_p1G) and one for rutile as identified in LT2_D (see Table 1). The main peak of magnesite (labelled in red) is present in both of them at 1093 and $1094 \mathrm{~cm}^{-1}$, since the two minerals are surrounded by carbonates, which have a strong signal. Both spectra were collected with the Horiba Xplora spectrometer; the star represents the neon lamp emission line at $476.8 \mathrm{~cm}^{-1}$ used for calibration. Peak positions are reported without decimals.

\subsubsection{Ultra Long Term Test}

The Ultra Long Term Test presents a widespread recrystallization of magnesite $\left(\mathrm{MgCO}_{3}\right)$ in the range of $77-100 \%$ (see Table 1 and Figures 9 and 10) along the entire core, and no alteration front was detectable anymore with Raman spectroscopy [40,60]. 


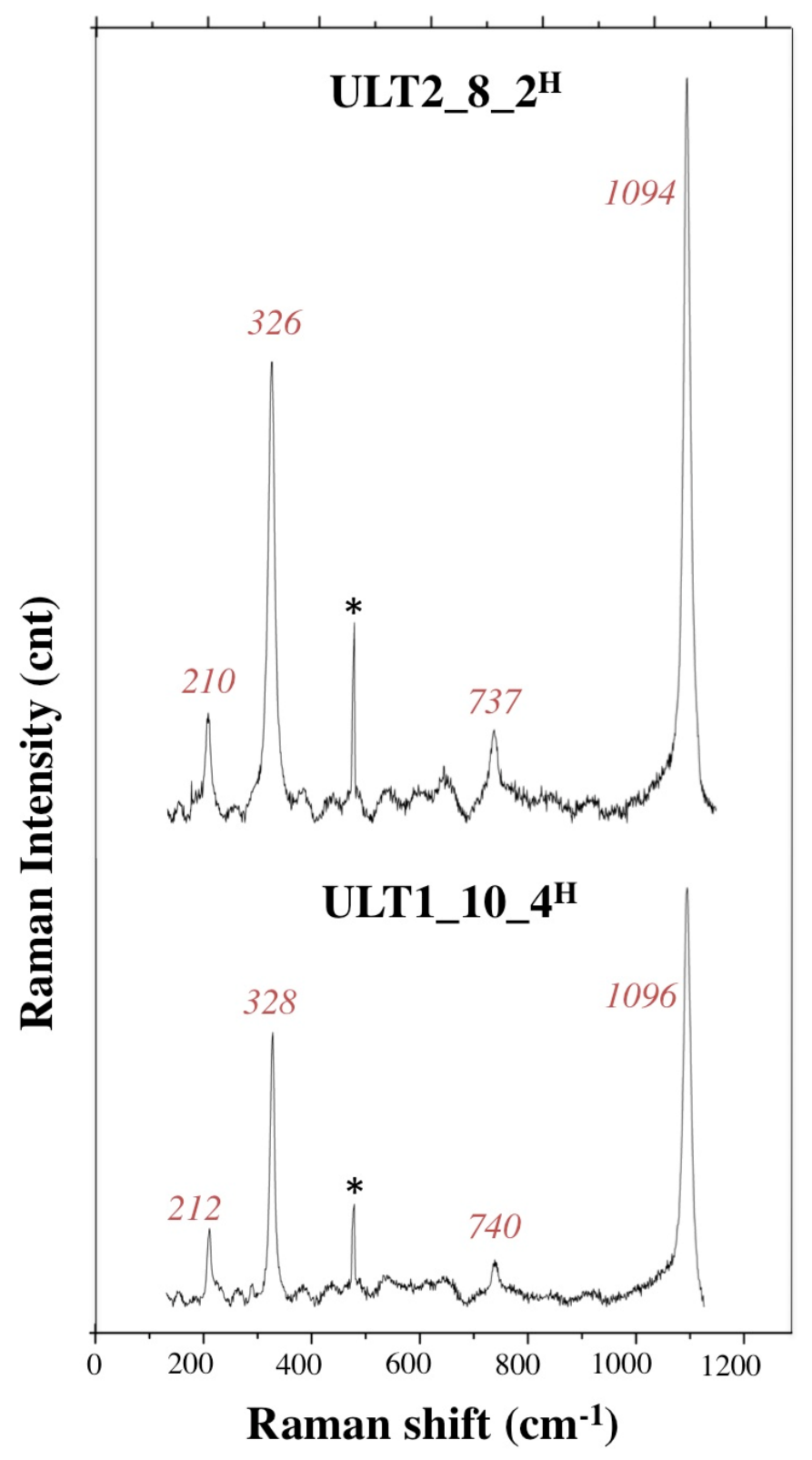

Figure 9. Raman spectra collected on the Ultra Long Term Test Raman showing the presence of recrystallized magnesite. Both spectra were collected with the Horiba XploRA spectrometer; stars represent the neon lamp emission line at $476.8 \mathrm{~cm}^{-1}$ used for calibration with the Horiba XploRA spectrometer. Peak positions are reported without decimals.

Raman spectra were collected in 9 different areas situated along the $7 \mathrm{~cm}$ core $(90$ spectra in total, see Table 1 and Figure 10). No structures or patterns are visible to the naked eye, and the core seems to be quite mineralogically homogeneous. Another study [54], made using ICP-MS (induced coupled plasma mass spectrometry), confirmed our data, as average of $4 \%$ of $\mathrm{CaO}$ was detected on the bulk sample, with no great difference in composition in the different portions of the sample. 


\section{Ultra Long Term Test}

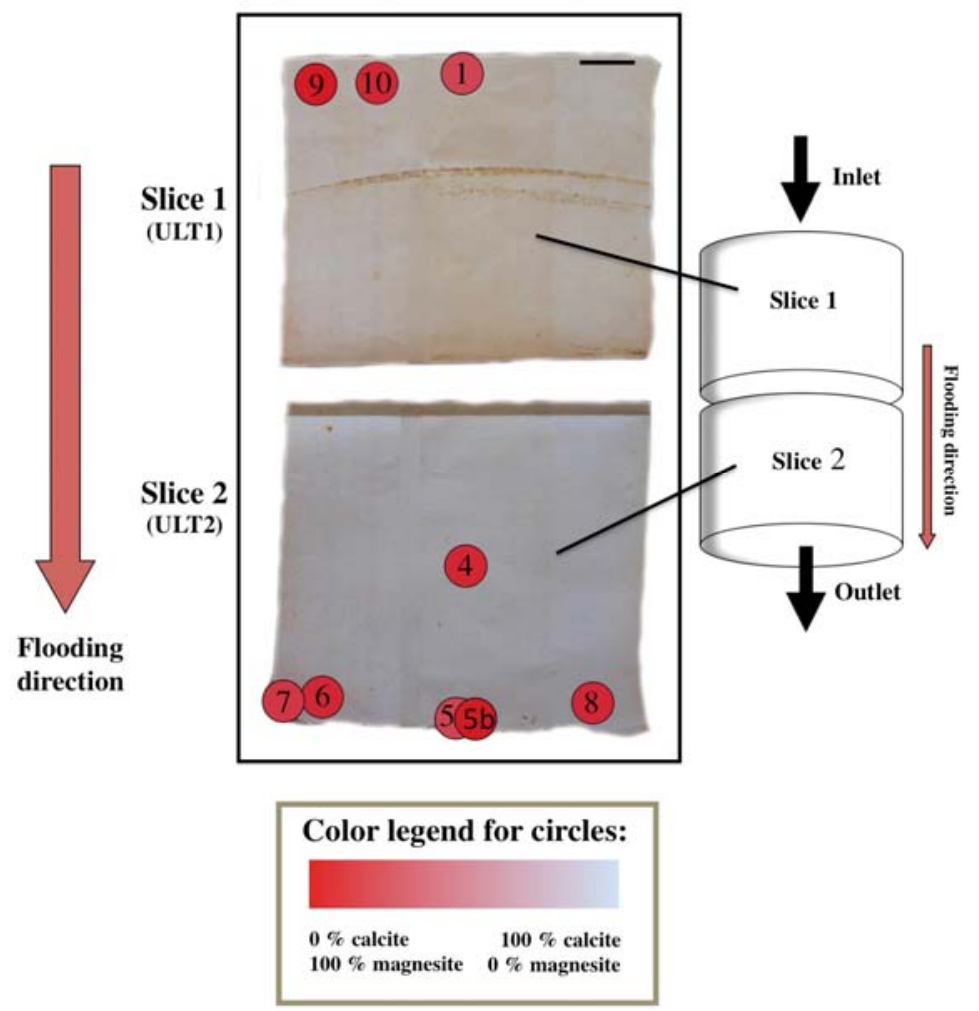

Figure 10. Mineralogical composition of the ULTT core: 10 spectra have been collected in each of the 9 areas shown. Color legend reflects the percentage of calcite and magnesite spectra collected in each area of the sample. See Table 1 for calcite and magnesite amounts and percentages obtained for each area. Flooding direction is indicated. The scale represents $0.5 \mathrm{~cm}$. A schematic drawing of how the cores were cut after the flooding experiment is shown to the right.

\section{Discussion}

This study represents the first attempt to apply Raman spectroscopy to chalk mineralogy with a single grain approach on micron scale. The very fine-grained and soft texture of this sedimentary rock made detailed analysis quite challenging with common methods, and for this reason, in recent years, several high performing techniques have been included in Enhanced Oil Recovery (EOR) research. The purpose of this methodology paper is to demonstrate that Raman spectroscopy, thanks to its quickness, low cost, and micrometric resolution, is very suitable for these studies as, in few seconds and without any sample preparation, a mineralogical identification and a semi-quantitative compositional evaluation can be provided. It is perfectly complementary to methods such as SEM-EDS or XRD.

The major alteration front in LTT was previously suggested between LT3 and LT4 [36]; however, by the use of Raman spectroscopy, it was possible to detect magnesite even in slice 4 (Table 1; Figure 7), when XRD studies could not be positive in this regard [36]. The calcite dissolution and magnesite recrystallization were massive in the first $2 \mathrm{~cm}$ of the core (slice 1 and 2 of LTT; Figure 7). LTT5 and LTT6 were not studied in this investigation, as in a previous study [36], these slices were found to be the least altered slices by the flooding unable to provide further information when applying the used methods. Raman spectroscopy confirmed that such an alteration front was no longer present within the ULTT, which means that in three years of $\mathrm{MgCl}_{2}$ injection, a sufficient quantity of $\mathrm{Mg}^{2+}$ was flooded into the core [40], permitting the substitution of almost all the $\mathrm{Ca}^{2+}$ to take place (92\% of magnesite Raman spectra; see Table 1 and Figure 10). 
The only precipitated mineral species that could be detected after flooding was magnesite. No dolomite, Mg-calcites, or hydrated minerals (such as hydromagnesite, artinite, and nesquehonite) were detected. As already seen with other techniques (SEM, XRD) applied in a previous study [36], it was not possible to identify clay-minerals in the two cores using Raman spectroscopy. It is very difficult to find a technique that could provide a resolution high enough to spot $<1 \mu \mathrm{m}$ crystals and simultaneously have the capability to cover a portion of the sample wide enough to detect a $\leq 5 \%$ component, in a quick way, and image it at the same time. A principle technique would be a Mineral Liberation Analyser (MLA) with a nanometer-small spot size, which is still technically challenging using electron-beams on such small scales, or a Nano-scale Secondary Ion Mass Spectrometer (nano-SIMS) [36] or nanoRaman (TERS, Tip Enhanced Raman Spectroscopy) [55,56] application coupled with an Atomic Force Microscope (AFM), which allows in collecting topography and mineralogical maps at the nano-scale but is very time-consuming. In the LTT sample, nano-crystals of quartz have been detected only by nano-SIMS [36], which is a very time-consuming and destructive methodology, is extraordinarily expensive, and is not quantitative. Another technique would be TEM-EDS (Transmission Electron Microscopy), with has the same drawbacks besides the fact that the latter reveals quantitative data along with mineral-identification through diffraction analysis [57]. Raman spectroscopy could be the tool to use but with the known limits of 1-2 micron spotsize and the impossibility of imaging the analyzed area with an optical microscope. An advance would be to scan an area, which is still a technical issue. A very low abundance of a mineral may be challenging to detect unless collecting a really huge number of spectra, which in turn would be time consuming. Furthermore, the identification of small and thin hydrated minerals is quite difficult to achieve in the $0-1200 \mathrm{~cm}^{-1}$ region of the Raman spectra, since their signal is weak and easily covered by the higher carbonate peaks. For this reason, we tried to detect them with a different setting of the instrumentation, moving the analyses to the high region of the Raman spectra, around $3500 \mathrm{~cm}^{-1}$, where the $\mathrm{OH}^{-}$ vibrational modes are present. Anhydrous minerals such as calcite and magnesite do not show peaks in this region. Unfortunately, no signal from phyllosilicates has been detected, possibly as a consequence of these technical difficulties.

Despite the impossibility of recognizing such low-concentrated and platy minerals, since the set-up is relatively economical and rapid, the authors think that Raman spectroscopy represents a very helpful methodology that could and should be used on hydrocarbon drilling rigs, possibly even as a drilling steering tool, because carefully investigations could show that positive and useful results were generated. This can lead to well-developed methodologies in the future for different approaches, like the petroleum industry.

\section{Conclusions}

The mineralogical and textural changes that follow dissolution, precipitation, and compaction in brine-injected chalk affect the permeability, porosity, reservoir potential, and oil flow pathways (e.g., $[8,21,36,53])$. For this reason, a deep investigation of secondary mineral recrystallization is of paramount importance in EOR research.

This study demonstrates that Raman spectroscopy is a robust, cheap, user-friendly point-analysis technique that, with a non-destructive sample preparation, allows one to quickly obtain semi-quantitative mineralogical and chemical information. This method has been applied to micron-sized chalk samples, giving an advantage in comparison to time consuming methods like SEM, thin section studies, nano-Raman or EMPA, and ion-probe analysis. An estimation of the magnesite recrystallization could be performed on two chalk cores that were flooded under reservoir conditions with $\mathrm{MgCl}_{2}$ : Long Term Test (1.5-years-test, LTT) and Ultra Long Term Test (3-years-test, ULTT). In the LTT, the average recrystallization is more pervasive close to the inlet surface and varies with flooding direction. ULTT is, on the other hand, quite homogeneous, as the alteration front is no longer visible, and the whole core predominantly consists of magnesite. 
However, not all reservoir rocks contain minerals and/or phases as small as those in chalk, which would make the here shown methodology very attractive. Anyway, when spectrometers with better analysis resolution and autofocus become available, Raman maps will be possible even on chalk cores samples, permitting to collect compositional maps and quantitative data analyses. Raman spectroscopy can, together with other research methods, provide a full range of information on flooded chalk cores leading to a broader understanding of chemical and mineralogical changes in those samples during the mentioned EOR experiments.

Until today, Raman spectroscopy has been only occasionally applied in the oil industry [61-64], and it is time for it to become a routine analysis.

Author Contributions: L.B. made a substantial contribution to every step of the study, such as the acquisition (with the fundamental help of N.E.) and interpretation of the data and writing of the paper. U.Z., L.B, M.W.M., and S.A. contributed to design and conception of the present publication. M.V.M. and R.I.K. designed and performed the long-term tests on the chalk cores. All the co-authors performed a critical revision of the intellectual content of the paper.

Acknowledgments: The authors acknowledge the Research Council of Norway and the industry partners ConocoPhillips Skandinavia AS, Aker BP ASA, Eni Norge AS, Maersk Oil Norway AS, Statoil Petroleum AS, ENGIE E\&P NORGE AS, Lundin Norway AS, Halliburton AS, Schlumberger Norge AS, Wintershall Norge AS, and DEA Norge AS of The National IOR Centre of Norway for support. This study is a central part of the PhD thesis of L.B., who thanks the NIOR Centre of Norway for a grant to carry out the research, and Eduardo Garzanti and the group of Provenance Studies (University of Milano-Bicocca) for their advice.

Conflicts of Interest: The authors declare no conflict of interest. The funding sponsors had no role in the design of the study; in the collection, analyses, or interpretation of data; in the writing of the manuscript; or in the decision to publish the results.

\section{References}

1. Hermansen, H.; Landa, G.H.; Sylte, J.E.; Thomas, L.K. Experiences after 10 years of waterflooding the Ekofisk Field, Norway. J. Pet. Sci. Eng. 2000, 26, 11-18. [CrossRef]

2. Nagel, N.B. Compaction and subsidence issues within the petroleum industry: From Wilmington to Ekofisk and beyond. Phys. Chem. Earth A 2001, 26, 3-14. [CrossRef]

3. Risnes, R.; Madland, M.V.; Hole, M.; Kwabiah, N.K. Water weakening of chalk-Mechanical effects of water-glycol mixtures. J. Pet. Sci. Eng. 2005, 48, 21-36. [CrossRef]

4. Heggheim, T.; Madland, M.V.; Risnes, R.; Austad, T. A chemical induced enhanced weakening of chalk by seawater. J. Pet. Sci. Eng. 2005, 46, 171-184. [CrossRef]

5. Korsnes, R.I.; Strand, S.; Hoff, Ø.; Pedersen, T.; Madland, M.V.; Austad, T. Does the chemical interaction between seawater and chalk affect the mechanical properties of chalk? In Multiphysics Coupling and Long Term Behaviour in Rock Mechanics; Cotthem, A.V., Charlier, R., Thimus, J.F., Tshibangu, J.P., Eds.; Taylor \& Francis: London, UK, 2006; pp. 427-434.

6. Korsnes, R.I.; Madland, M.V.; Austad, T.; Haver, S.; Rosland, G. The effects of temperature on the water weakening of chalk by seawater. J. Pet. Sci. Eng. 2008, 60, 183-193. [CrossRef]

7. Madland, M.V.; Midtgarden, K.; Manafov, R.; Korsnes, R.I.; Kristiansen, T.; Hiorth, A. The Effect of Temperature and Brine Composition on the Mechanical Strength of Kansas Chalk. In Proceedings of the International Symposium of the Society of Core Analysts, Abu Dhabi, UAE, 29 October-2 November 2008.

8. Madland, M.V.; Hiorth, A.; Omdal, E.; Megawati, M.; Hildebrand-Habel, T.; Korsnes, I.R.; Evje, S.; Cathles, M.L. Chemical alterations induced by rock-fluid interactions when injecting brines in high porosity chalks. Transp. Porous Med. 2011, 87, 679-702. [CrossRef]

9. Zangiabadi, B.; Korsnes, R.I.; Hildebrand-Habel, T.; Hiorth, A.; Surtarjana, I.K.; Lian, A.; Madland, M.V. Chemical water weakening of various outcrop chalks at elevated temperature. In Poromechanics IV ; Ling, H.I., Smyth, A., Betti, R., Eds.; DEStech Publications, Inc.: Lancaster, UK, 2009; pp. 543-548.

10. Andreassen, K.A.; Fabricius, I.L. Biot critical frequency applied to description of failure and yield of highly porous chalk with different pore fluids. Geophysics 2010, 75, E205-E213. [CrossRef]

11. Zhang, P.; Tweheyo, M.T.; Austad, T. Wettability alteration and improved oil recovery by spontaneous imbibition of seawater into chalk: Impact of the potential determining ions $\mathrm{Ca}^{2+}, \mathrm{Mg}^{2+}$, and $\mathrm{SO}_{4}{ }^{2+}$. Colloids Surf. A Physicochem. Eng. Aspects 2007, 301, 199-208. [CrossRef] 
12. Strand, S.; Hjuler, M.L.; Torsvik, R.; Pedersen, J.I.; Madland, M.V.; Austad, T. Wettability of chalk: Impact of silica, clay content and mechanical properties. Pet. Geosci. 2007, 13, 69-80. [CrossRef]

13. Austad, T.; Strand, S.; Madland, M.V.; Puntervold, T.; Korsnes, R.I. Seawater in chalk: An EOR and compaction fluid. SPE Reserv. Eval. Eng. 2008, 11, 648-654. [CrossRef]

14. Hiorth, A.; Cathles, L.; Madland, M. The Impact of Pore Water Chemistry on Carbonate Surface Charge and Oil Wettability. Transp. Porous Med. 2010, 85, 1-21. [CrossRef]

15. Fathi, S.J.; Austad, T.; Strand, S. "Smart Water" as a Wettability Modifier in Chalk: The Effect of Salinity and Ionic Composition. Energy Fuels 2010, 24, 2514-2519. [CrossRef]

16. Ali, A.Y.; Salah Hamad, A.S.; Abdulaziz, A.K.; Mohammed Saleh, A.J. Laboratory Investigation of the Impact of Injection Water Salinity and Ionic Content on Oil Recovery from Carbonate Reservoirs. SPE Reserv. Eval. Eng. 2011. [CrossRef]

17. Megawati, M.; Hiorth, A.; Madland, M.V. The impact of surface charge on the mechanical behavior of high-porosity chalk. Rock Mech. Rock Eng. 2013, 46, 1073-1090. [CrossRef]

18. Zhang, P.; Tweheyo, M.T.; Austad, T. Wettability Alteration and Improved Oil Recovery in Chalk: The Effect of Calcium in the Presence of Sulfate. Energy Fuels 2006, 20, 2056-2062. [CrossRef]

19. Andersen, P.Ø.; Evje, S.; Madland, M.V.; Hiorth, A. A geochemical model for interpretation of chalk core flooding experiments. Chem. Eng. Sci. 2012, 84, 218-241. [CrossRef]

20. Megawati, M.; Madland, M.V.; Hiorth, A. Mechanical and physical behavior of high-porosity chalks exposed to chemical perturbation. J. Pet. Sci. Eng. 2015, 133, 313-327. [CrossRef]

21. Wang, W.; Madland, M.V.; Zimmermann, U.; Nermoen, A.; Reidar, I.; Korsnes, R.; Bertolino, S.R.A.; Hildebrand-Habel, T. Evaluation of porosity change during chemo-mechanical compaction in flooding experiments on Liege outcrop chalk. In Reservoir Quality of Clastic and Carbonate Rocks: Analysis, Modelling and Prediction; Armitage, P.J., Butcher, A.R., Churchill, J.M., Csoma, A.E., Hollis, C., Lander, R.H., Omma, J.E., Worden, R.H., Eds.; Geological Society: London, UK, 2016; p. 435.

22. Raman, C.V. A new radiation. Indian J. Phys. 1928, 2, 387-398.

23. Krishnamurti, D. Raman spectrum of magnesite. Proc. Indian Acad. Sci. Sect. A 1956, 43, 210.

24. Griffith, W.P. Raman spectroscopy of minerals. Nature 1969, 224, 264-266. [CrossRef]

25. Kuebler, K.; Wang, A.; Abbott, K.; Haskin, L.A. Can we detect carbonate and sulfate minerals on the surface of Mars by Raman spectroscopy? In Proceedings of the 32nd Annual Lunar and Planetary Science Conference, Houston, TX, USA, 12-16 March 2001.

26. Downs, R.T. The RRUFF Project: An integrated study of the chemistry, crystallography, Raman and infrared spectroscopy of minerals. In Proceedings of the 19th General Meeting of the International Mineralogical Association, Kobe, Japan, 23-28 July 2006.

27. Andò, S.; Garzanti, E. Raman spectroscopy in heavy-mineral studies. In Sediment Provenance Studies in Hydrocarbon Exploration and Production; Scott, R.A., Smyth, H.R., Morton, A.C., Richardson, N., Eds.; Geological Society: London, UK, 2013; p. 386.

28. Gillet, P.; Biellmann, C.; Reynard, B.; McMillan, P. Raman spectroscopic studies of carbonates Part I: High-pressure and high-temperature behaviour of calcite, magnesite, dolomite and aragonite. Phys. Chem. Miner. 1993, 20, 1-18. [CrossRef]

29. Bendel, V.; Schmidt, B.C. Raman spectroscopic characterisation of disordered alkali feldspars along the join $\mathrm{KAlSi}_{3} \mathrm{O}_{8}-\mathrm{NaAlSi}_{3} \mathrm{O}_{8}$ : Application to natural sanidine and anorthoclase. Eur. J. Miner. 2008, 20, 1055-1065. [CrossRef]

30. Noguchi, N.; Abduriyim, A.; Shimizu, I.; Kamegata, N.; Odake, S.; Kagi, H. Imaging of internal stress around a mineral inclusion in a sapphire crystal: Application of micro-Raman and photoluminescence spectroscopy. JRS 2013, 44, 147-154. [CrossRef]

31. De La Pierre, M.; Carteret, C.; Maschio, L.; André, E.; Orlando, R.; Dovesi, R. The Raman spectrum of $\mathrm{CaCO}_{3}$ polymorphs calcite and aragonite: A combined experimental and computational study. J. Chem. Phys. 2014, 140, 164509. [CrossRef] [PubMed]

32. Del Monte, B.; Paleari, C.I.; Andò, S.; Garzanti, E.; Andersson, P.S.; Petit, J.R.; Crosta, X.; Narcisi, B.; Baroni, C.; Salvatore, M.C.; et al. Causes of dust size variability in central East Antarctica (Dome B): Atmospheric transport from expanded South American sources during Marine Isotope Stage 2. Quat. Sci. Rev. 2017, 168, 55-68. [CrossRef] 
33. Molenaar, N.; Zijlstra, J.J.P. Differential early diagenetic low-Mg calcite cementation and rhythmic hardground development in Campanian-Maastrichtian chalk. Sediment. Geol. 1997, 109, 261-281. [CrossRef]

34. Robaszynski, F.; Dhondt, A.V.; John, W.M. Cretaceous lithostratigraphic units (Belgium). Geol. Belg. 2001, 4, 121-134.

35. Hjuler, M.L.; Fabricius, I.L. Engineering properties of chalk related to diagenetic variations of Upper Cretaceous onshore and offshore chalk in the North Sea area. J. Pet. Sci. Eng. 2009, 68, 151-170. [CrossRef]

36. Zimmermann, U.; Madland, M.V.; Nermoen, A.; Hildebrand-Habel, T.; Bertolino, S.A.R.; Hiorth, A.; Korsnes, R.I.; Audinot, J.N.; Grysan, P. Evaluation of the compositional changes during flooding of reactive fluids using scanning electron microscopy, nano-secondary ion mass spectroscopy, X-ray diffraction, and whole-rock geochemistry. AAPG Bull. 2015, 99, 791-805. [CrossRef]

37. Hjuler, M.L. Diagenesis of Upper Cretaceous Onshore and Offshore Chalk from the North Sea Area. Ph.D. Thesis, Department of Civil Engineering, Arctic Technology Centre, Technical University of Denmark, Kongens Lyngby, Denmark, 2007.

38. Felder, R.M.; Spence, R.D.; Ferrell, J.K. A method for the dynamic measurement of diffusivities of gases in polymers. J. Polym. Sci. 1975, 19, 3193-3200. [CrossRef]

39. Slimani, H. New species of dinoflagellate cysts from the Campanian-Danian chalks at Hallembaye and Turnhout (Belgium) and at Beutenaken (The Netherlands). J. Micropalaeontol. 2001, 20, 1-11. [CrossRef]

40. Nermoen, A.; Korsnes, R.I.; Hiorth, A.; Madland, M.V. Porosity and permeability development in compacting chalks during flooding of nonequilibrium brines: Insights from long-term experiment. JGR Solid Earth 2015, 120, 2935-2960. [CrossRef]

41. Rutt, H.N.; Nicola, H.J. Raman spectra of carbonates of calcite structure. Phys. C Solid State Phys. 1974, 7, 4522. [CrossRef]

42. Bischoff, W.D.; Sharma, S.K.; MacKenzie, F.T. Carbonate ion disorder in synthetic and biogenic magnesian calcites: A Raman spectral study. Am. Miner. 1985, 70, 581-589.

43. Herman, R.G.; Bogdan, C.E.; Sommer, A.J.; Simpson, D.R. Discrimination among carbonate minerals by Raman spectroscopy using the laser microprobe. Appl. Spectrosc. 1987, 41, 437-440. [CrossRef]

44. Edwards, H.; Villar, S.; Jehlicka, J.; Munshi, T. FT-Raman spectroscopic study of calcium-rich and magnesium-rich carbonate minerals. Spectrochim. Acta A 2005, 61, 2273. [CrossRef] [PubMed]

45. Korsakov, A.; De Gussem, K.; Zhukov, V.P.; Perraki, M.; Vandenabeele, P.; Golovin, A.V. Aragonite-calcitedolomite relationships in UHPM polycrystalline carbonate inclusions from the Kokchetav Massif, northern Kazakhstan. Eur. J. Miner. 2009, 21, 1301. [CrossRef]

46. Borromeo, L.; Zimmermann, U.; Andò, S.; Coletti, G.; Bersani, D.; Basso, D.; Gentile, P.; Schulz, B.; Garzanti, E. Raman spectroscopy as a tool for magnesium estimation in Mg-calcite. JRS 2017, 48, 983-992. [CrossRef]

47. Dandeu, A.; Humbert, B.; Carteret, C.; Muhr, H.; Plasari, E.; Bossoutrot, J.M. Raman Spectroscopy-A Powerful Tool for the Quantitative Determination of the Composition of Polymorph Mixtures: Application to $\mathrm{CaCO}_{3}$ Polymorph Mixtures. Chem. Eng. Technol. 2006, 29, 221-225. [CrossRef]

48. Sun, J.; Zeguang, W.; Hongfei, C. A Raman spectroscopic comparison of calcite and dolomite. Spectrochim. Acta A 2014, 117, 158. [CrossRef] [PubMed]

49. Purgstaller, B.; Mavromatis, V.; Immenhauser, A.; Dietzel, M. Transformation of Mg-bearing amorphous calcium carbonate to Mg-calcite-In situ monitoring. Geochim. Cosmochim. Acta 2016, 174, 180-195. [CrossRef]

50. Krishnan, R.S. Raman spectra of the second order in crystals; part. I: Calcite. Proc. Math. Sci. 1945, $22,182$.

51. White, W.B. Infrared Spectra of Minerals; Farmer, V.C., Ed.; Mineralogical Society Monograph 4; Mineralogical Society: London, UK, 1974; pp. 87-110, 227-284.

52. Urmos, J.; Sharma, S.K.; Mackenzie, T. Characterization of some biogenic carbonates with Raman spectroscopy. Am. Miner. 1991, 76, 641-646.

53. Minde, M.W.; Haser, S.; Korsnes, R.I.; Zimmermann, U.; Madland, M.V. Comparative Studies of Mineralogical Alterations of Three Ultra-long-term Tests of Onshore Chalk at Reservoir Conditions. In Proceedings of the IOR 2017-19th European Symposium on Improved Oil Recovery 2017, Stavanger, Norway, 24-27 April 2017.

54. Minde, M.W.; Zimmermann, U.; Madland, M.V.; Korsnes, R.I. Submicron Investigations—What Can We Learn? IOR: Stavanger, Norway, 2016; Available online: http:/ / www.uis.no/getfile.php/13300942/IOR-senter/ IOR_16_MMinde\%20-\%20dag\%202_theme\%205.pdf (accessed on 18 May 2018). 
55. Borromeo, L.; Minde, M.; Toccafondi, C.; Zimmermann, U.; Andò, S.; Ossikovski, R. A New Frontier Technique for Nano-analysis on Flooded Chalk-TERS (Tip Enhanced Raman Spectroscopy). In Proceedings of the IOR 2017-19th European Symposium on Improved Oil Recovery, Stavanger, Norway, 24-27 April 2017.

56. Borromeo, L.; Toccafondi, C.; Minde, M.; Zimmermann, U.; Andò, S.; Madland, M.V.; Korsnes, R.I.; Ossikovski, R. Application of Tip Enhanced Raman Spectroscopy in the nanoscale characterization of flooded chalk. JRS 2018. submitted.

57. Egeland, N.; Minde, M.W.; Kobayashi, K.; Ota, T.; Nakamura, E.; Zimmermann, U.; Madland, M.W.; Korsnes, R.I. Quantification of Mineralogical Changes in Flooded Carbonate under Reservoir Conditions. In Proceedings of the IOR 2017-19th European Symposium on Improved Oil Recovery, Stavanger, Norway, 24-27 April 2017.

58. Frezzotti, M.L.; Tecce, F.; Casagli, A. Raman spectroscopy for fluid inclusion analysis. J. Geochem. Explor. 2012, 112, 1-20. [CrossRef]

59. Wang, A.; Freeman, J.J.; Jolliff, B.L. Understanding the Raman spectral features of phyllosilicates. JRS 2015, 46, 829-845. [CrossRef]

60. Egeland, N. Raman Spectroscopy Applied to Enhanced Oil Recovery. Master's Thesis, University of Stavanger, Stavanger, Norway, 2015, unpublished.

61. Gorelik, V.S.; Chervyakov, A.V.; Kol'tsova, L.V.; Veryaskin, S.S. Raman Spectra of Saturated Hydrocarbons and Gasolines. J. Russ. Laser Res. 2000, 21, 323-334. [CrossRef]

62. Costa, J.C.S.; Sant'Ana, A.C.; Corio, P.; Temperini, M.L.A. Chemical analysis of polycyclic aromatic hydrocarbons by surface-enhanced Raman spectroscopy. Talanta 2006, 70, 1011-1016. [CrossRef] [PubMed]

63. Sebek, J.; Pele, L.; Potma, E.O.; Gerber, R.B. Raman spectra of long chain hydrocarbons: Anharmonic calculations, experiment and implications for imaging of biomembranes. PCCP 2011, 13, 12724-12733. [CrossRef] [PubMed]

64. Andrews, A.B.; Wang, D.; Marzec, K.M.; Mullins, O.C.; Crozier, K.B. Surface enhanced Raman spectroscopy of polycyclic aromatic hydrocarbons and molecular asphaltenes. Chem. Phys. Lett. 2015, 620, 139-143. [CrossRef] 